\title{
ANÁLISE DO PROCESSO DE DESENVOLVIMENTO DO PENSAMENTO CONCEITUAL NA ESCOLA
}

${ }^{1}$ Vinicius dos Santos Oliveira, ${ }^{2}$ Irineu Aliprando Tuim Viotto Filho

'Universidade Estadual Paulista - UNESP, Mestrado em Educação. Universidade do Oeste Paulista - UNOESTE, Curso de Psicologia. Presidente Prudente, SP. ${ }^{2}$ Pontifícia Universidade Católica de São Paulo - PUC, Doutorado em Educação, São Paulo, SP. E-mail:viniciusoliveira@unoeste.br

\section{RESUMO}

O presente artigo é resultado de uma pesquisa de mestrado em educação escolar que tem como objetivo analisar a importância dos conhecimentos científicos e respectivos conceitos, para o processo de desenvolvimento do pensamento conceitual dos estudantes durante as aulas de língua portuguesa numa escola de ensino fundamental de presidente prudente. Tem como base a teoria histórico-cultural e a pedagogia histórico-crítica e participaram do estudo seis alunos de uma escola pública da periferia da cidade. Após realização de processo de intervenção conclui-se que os sujeitos participantes encontram-se em processo de desenvolvimento do pensamento em conceitos, no entanto ainda não desenvolveram a capacidade de operar com os mesmos, situação decorrente de uma certa carência no seu processo educativo escolar.

Palavras-chave: Pensamento conceitual; formação de conceitos; educação escolar; teoria históricocutural; pedagogia histórico-crítica.

\section{ANALYSIS OF DEVELOPMENTAL PROCESS OF CONCEPTUAL THOUGHT AT SCHOOL}

\section{ABSTRACT}

This article is the result of a master'research in education that aimed to analyze the importance of scientific knowledge and its concepts to the process of development of conceptual thought in the Portuguese classes of an Elementary school at Presidente Prudente/SP. The intervention process is based on the historical-cultural theory and historical- critical pedagogy and it is being done inside the school. The participants were students who comes from a public school and the conclusion is that their development is in process and the conceptual thought have been building, but they do not have the ability to operate with the concepts properly and it is a kind of deficiency in the educational process.

Keywords: conceptual thought at school; historical-cutural theory; historical- critical pedagogy. 


\section{INTRODUÇÃO}

O psiquismo humano é compreendido pela teoria histórico-cultural como uma unidade dialética material ideal que possibilita a formação da "imagem subjetiva da realidade objetiva", processo engendrado através de um sistema psíquico interfuncional complexo, como afirma Martins (2013, p. 288). O psiquismo é material por ter como base questões orgânicas, biológicas e físicas, ou seja, o cérebro e, ao mesmo tempo, é ideal à medida que cada ser humano representa o mundo real de forma subjetiva.

Este sistema interfuncional complexo é composto por funções psíquicas, quais sejam sensação, percepção, atenção e memória, pensamento, linguagem e imaginação, dentre outras eminentemente humanas, as quais são funções psíquicas responsáveis pela formação e organização da imagem subjetiva da realidade e por fim as funções de emoções e sentimentos, as chamadas funções afetivas e responsáveis por conferirem caráter pessoal ao psiquismo (MARTINS, 2011 e 2012).

Segundo Vygotski (2014) o pensamento como função psicológica superior passa por três fases, quais sejam, o pensamento sincrético, o pensamento por complexos e o pensamento por conceitos, sendo que as duas primeiras fases ainda subdividem-se em outras etapas. O pensamento sincrético, característico dos anos iniciais de vida da criança, passa pelas etapas de tentativa e erro, organização temporal e espacial e por fim, por subagrupamento desordenado de idéias. Nesta fase a criança ainda não compreende bem as palavras e portanto, em muitos momentos, sente-se confusa ao lidar com os significados das palavras. Ainda não domina os espaços, seu desenvolvimento motor é incipiente, embora manipule objetos, não compreende suas funções; além disso, confunde-se no reconhecimento do tempo e não distingue hoje, ontem e amanhã, dentre outras dificuldades de relação e reconhecimento da realidade.

O pensamento por complexo, fase seguinte que a criança atinge com um pouco mais de idade, passa por outras cinco divisões, quais sejam, o complexo associativo, complexo por coleção, complexo em cadeia, complexo difuso e por fim os pseudoconceitos, fases que implicam a paulatina complexificação do pensamento da criança. Vygotski (2014) explica que o complexo associativo, baseia-se em qualquer conexão associativa, em que há uma característica que sirva como núcleo para associar as demais. Ele parte de qualquer relação entre o núcleo e outros elementos para reunir elementos novos. Os elementos não precisam estar relacionados entre si, pois há uma relação heterogênea, desordenada, assistemática e incoerente.

Na etapa seguinte, o complexo por coleção caracteriza-se por um agrupamento especial de informações, que remete a uma coleção em que a criança junta objetos, levando em conta um determinado atributo que é complementar a todos, podendo unir coisas diferentes, mas complementares de alguma forma. É um período estável e duradouro.

Segundo Vygotski (2014) o complexo em cadeia, o próxima dentre os complexos, é marcado por uma união dinâmica e sequencial de ligações individuais em uma única cadeia, a qual é formada por sucessivos links e conexões associativas, no entanto, entre elementos distintos. Cada ligação entre elementos pode não ter ligação com o núcleo (modelo), sendo que este núcleo tem o mesmo peso e importância que os demais elementos de ligação, podendo não existir um centro estrutural para o encadeamento das informações. No complexo em cadeia, o primeiro e o terceiro elementos, podem não ter nenhuma ligação entre si, exceto que ambos se relacionam com o segundo.

O próximo complexo é chamado de difuso, pois é um tipo de pensamento marcado pela junção de coisas pelos seus atributos e características fundamentais, ainda que de elementos difusos, indeterminados e vagos. Neste complexo são formadas famílias de coisas e associam-se a esse grupo objetos alheios ao conhecimento prático da criança, fato que permite apoio em atributos 
indeterminados e vagos, nem sempre compatíveis entre si, porém, no pensamento da criança, plenamente possíveis, ainda que difusos.

Em relação aos pseudoconceitos, Vygotski (2014) diz que eles constituem-se como equivalentes funcionais dos conceitos, justamente por manterem características externas a um conceito verdadeiro. Ou seja, a fala das crianças não se diferencia da fala dos adolescentes e adultos, no entanto, a diferença é encontrada na forma de compreensão interna desta fala pela criança, uma vez que o significado atribuído pela criança à determinada palavra pode não ser o mesmo atribuído pelo adulto, isso para a mesma palavra.

O autor continua dizendo que uma análise atenta deste tipo de complexo, o pseudoconceito, revela um complexo internamente, mas externamente, se parece plenamente com um conceito, fato que dificulta a diferenciação entre o pseudoconceito e o conceito e que requer uma análise cuidadosa.

Por fim, a fase do pensamento em conceitos propriamente dito é acessível ao indivíduo na adolescência, porém não surge de forma natural, necessita do ensino, portanto da atividade educativa de qualidade e que possibilite a apropriação de conceitos científicos e essenciais para o avanço qualitativo do pensamento humano.

Para Vygotski (2012) a função do pensamento se torna função reitora e guia de todo o desenvolvimento do psiquismo, sobretudo quando se conquista e se desenvolve para pensamento conceitual. A característica principal desta fase é o surgimento de uma nova forma de compreender o mundo, pois o conceito, segundo Martins (2011) e Anjos(2013) é compreendido como uma síntese de conhecimentos sobre determinado objeto ou fenômeno. De forma subjetiva, o conceito representa a realidade dos objetos que são encontrados na realidade objetiva, sendo que, somente por meio da mediação dos conceitos, é possível que a realidade seja apreendida como síntese de múltiplas determinações, em sua origem e em seu desenvolvimento.

Existem dois tipos principais de conceitos para Vygotski (2009 e 2014), os espontâneos e os científicos, os primeiros se formam no cotidiano, na convivência diária entre as pessoas, por isso não necessita da mediação do ensino. Os segundos, surgem como síntese de conhecimentos científicos, necessitam, portanto, da mediação e do trabalho educativo, portanto a presença e atuação do professor na escola tornam-se imprescindíveis.

Martins (2011 E 2012) afirma que é papel da educação escolar possibilitar ao estudante a apropriação e assimilação dos conceitos científicos, os quais devem superar os conceitos adquiridos cotidianamente. Podemos dizer que é função da escola possibilitar acesso e apropriação dos conhecimentos sistematizados pelas ciências, pela filosofia e outras objetivaçaões genéricas e universais construídas pela humanidade.

Socializar os conhecimentos sistematizados é uma atribuição específica da escola, como nos propõe Saviani (2005) ao afirmar que o trabalho educativo é uma atividade que deve produzir, de forma direta e intencional, em cada indivíduo singular, a humanidade construída histórica e coletivamente pelo conjunto dos homens. Ou seja, a humanidade construiu a ciência, a filosofia, as artes, a política, a ética,e outros conhecimentos genéricos, sendo que é papel da escola e do professor, criar condições para que os estudantes, na escola, possam apropriar-se desses conhecimentos para poderem aprender e se desenvolver como seres humanos humanizados.

Nossa pesquisa, desenvolvida no interior da escola procurou, na socialização de conceitos oriundos da língua portuguesa, analisar a importância da apropriação de tais conhecimentos e diferentes conceitos, para o processo de desenvolvimento do pensamento conceitual dos estudantes de uma sala de aula do Ensino Fundamental. 


\section{METODOLOGIA}

O presente trabalho é fruto de uma pesquisa de mestrado em educação escolar com ênfase em psicologia da educação. Para a construção deste artigo, foi feito um recorte dos dados coletados durante as intervenções com os estudantes, as quais foram realizadas no interior da escola.

\section{PARTICIPANTES}

Participaram desta pesquisa seis alunos do quarto ano do ensino fundamental em 2015 e quinto ano em 2016 de uma escola pública de Presidente prudente. Todos os participantes têm dez anos de idade e estão na mesma turma. Foram três do sexo feminino e três do sexo masculino.

\section{INSTRUMENTOS}

Foram realizadas observações sistemáticas que foram registradas em diário de campo. As observações foram nas aulas de língua portuguesa com objetivo de conhecer a turma e identificar os conceitos trabalhados pela professora. Posteriormente foram realizados encontros de intervenção com as crianças e estes foram filmados para maior aprofundamento da análise.

\section{PROCEDIMENTOS}

Este projeto está devidamente cadastrado na Plataforma Brasil, bem como no Comitê de ética em Pesquisa da Unesp de Presidente Prudente, CAAE: 48244215.9.0000.5402 e Número do Parecer: 1.209.002. Portanto, os participantes assinaram ao termo de assentimento livre e esclarecido e seus responsáveis ao termo de consentimento livre e esclarecido.

Foram escolhidos alguns conceitos científicos veiculados na aula de língua portuguesa que versavam sobre gêneros textuais, tais como: conto, biografia, autobiografia, notícia e reportagem. Foram realizados 16 encontros de intervenção com intuito de cumprir o objetivo principal desta pesquisa no sentido de analisar a importância dos conhecimentos científicos para o processo de desenvolvimento do pensamento conceitual, sendo que as intervenções tinham a seguinte estrutura.

No primeiro momento o pesquisador realizava perguntas relacionadas aos conceitos oriundos dos gêneros textuais, visando compreender o quando os participantes conheciam sobre os mesmos, assim como as características de cada gênero textual, dentre outras questões que visavam compreender o processo de conhecimento dos sujeitos. Em seguida era explicado de forma breve cada conceito e novamente questionava-se os participantes sobre o que eles se recordavam acerca dos conceitos. Por fim, era solicitado que os sujeitos escrevessem um texto sobre determinado gênero em questão.

\section{RESULTADOS}

Neste item apresentaremos um recorte de algumas falas dos participantes, especificamente sobre os conceitos de biografia e autobiografia, para que no próximo tópico, seja discutida a possível apropriação ou não dos conceitos por parte dos sujeitos da pesquisa.

Quando questionados o que era uma autobiografia, algumas respostas foram: "falar da sua vida, onde você nasceu"; "o nome da pessoa e idade"; "o nome da pessoa, idade, o dia do aniversário"; "as coisas mais importantes"; "falar da própria vida"; "alguém que escreve a própria vida"; "é quando fala da sua própria vida"; "contar sua vida".

Quanto ao conceito de biografia foram dadas as seguintes respostas: "A biografia fala sobre a história do autor"; "fala sobre a história? (do autor de um livro)"; "ai... conta a história sobre o autor e o livro dele"; "alguém que escreve da vida do outro"; "a biografia é contar a história de outra pessoa"; "tipo, é uma biografia, eu falar da vida dela" (apontando para uma colega); "falar de outra pessoa". 
Sobre a diferença desses conceitos, os sujeitos da pesquisa disseram que "a diferença da biografia e da autobiografia é que a biografia conta a história da vida de alguém"; "diferença é que uma é do outro e uma é a sua".

Quando escreveram sobre os conceitos de autobiografia e biografia, de modo geral, os textos não apresentaram as características essenciais destes tipos de gênero textual, pois, segundo Kaufman e Rodrígues (1995) a biografia é um texto narrativo feito por alguém sobre a vida de outra pessoa, porém quando o próprio autor conta sua história é uma autobiografia. Algumas das principais características deste texto é que, em geral, é escrito em ordem cronológica, com recursos linguísticos que demarquem a temporalidade.

Geralmente os textos dos sujeitos da pesquisa começavam pelo nome, idade, falavam da escola que estudam, passavam para coisas que mais gostam de fazer e retornavam para eventos e acontecimentos anteriores. Focaram em relatar o que gostam e o que gostariam de ser quando crescer.

\section{DISCUSSÃO}

As respostas apresentadas acima demonstram momentos de oscilação entre os tipos de pensamento por complexo associativo, por coleção e os pseudoconceitos. Quando determinado sujeito respondeu que a biografia conta a história do autor, é necessário ressaltar que durante as aulas a professora realizava uma leitura diária e ao final realizava a leitura da biografia do autor do livro, por isso os alunos associavam à esta idéia.

Segundo Vygotski (2014) o complexo associativo tem como característica associar as idéias conforme um elemento que possa ser o núcleo que liga este elemento a outros, por isso pode-se inferir que respostas como a do sujeito acima, corrobora esta forma de pensamento.

Quanto ao complexo por coleção, Vygotski (2014) revela que é um agrupamento especial de coisas que se assemelha a uma coleção, pois junta objetos levando em conta um determinado atributo que o complementa. No complexo por seleção, coisas diferentes e complementares, de alguma forma se unem por estar enraizado na experiência concreta, visual-prática do sujeito. Este complexo ainda possibilita formar conjuntos, partindo do principio da complementariedade funcional, baseado em conexões e relações presentes na ação prática vivida pelo sujeito.

Neste caso quando as crianças responderam que autobiografia é "falar da sua vida, onde você nasceu"; "o nome da pessoa e idade"; "o nome da pessoa, idade, o dia do aniversário" elas estão demonstrando uma capacidade de juntar informações por complementaridade, confirmando a proposição de Vygotski (2014) para a efetivação desta forma de pensamento, por coleção, conforme foi possível constatar.

Quanto aos pseudoconceitos, falas que apresentam ideias corretas sobre os conceitos, identificamos as seguintes expressões verbais: "tipo, é uma biografia, eu falar da vida dela" (apontando pra uma colega); "falar de outra pessoa, sendo que tem que ser escrito na ordem da vida", ou seja, tais falas indicam coerência côo o pseudoconceito, cujo qual é compreendido como o equivalente funcional aos conceitos apenas na aparência, como afirma Vigotski (2014), vez que, os sujeitos, quando solicitados a escreverem sobre o conceito de biografia e autobiografia não fizeram da forma que falaram, situação que, para nós, demonstra a fase do pseudoconceito que, aparentemente mostra-se como conceito, no entanto, no entanto na sua essência, ainda não avançou e consolidou-se como conceito. 


\section{CONCLUSÃO}

Conclui-se até o presente, que os sujeitos não demonstraram, até o momento, uma forma de pensar por conceitos verdadeiros, mas sim, por pseudoconceitos, talvez por uma falta de mediação qualitativamente diferenciada no trabalho educativo do professor, assim como, pela dificuldade de compreensão do próprio livro didático utilizado em aula, pois observamos que o livro didático não trás explicações do que são os conceitos, na verdade, não define os gêneros textuais, mas apenas apresenta textos relacionados aos mesmos, deixando para os alunos a compreensão do conceito, pela via da relação com os textos, fato que para nós implica uma limitação do livro didático.

Observamos, também, que não há uma explicação sistemática por parte da professora dos respectivos conceitos, assim sendo, além da idade de desenvolvimento dos sujeitos ser um empecilho para o seu ingresso no pensamento conceitual, alia-se a isso, a limitação do livro didático e a deficiência presente no processo educativo, situações que, de certa forma, dificultam o processo de aprendizagem, apropriação e incorporação dos conceitos para que o pensamento dos sujeitos avance e se desenvolva em direção ao plano do pensamento conceitual.

Em determinadas respostas, os alunos se aproximam dos conceitos, mas o pensamento em conceitos só é verificado quando o sujeito é colocado na prática e, conforme constatamos, na prática os alunos não demonstraram a apropriação e internalização dos conceitos e nem mesmo o pensar por conceitos, vez que, pensar por conceitos significa, sobretudo, conseguir operar com o conceito e não apenas explicar oralmente o mesmo pois, para operar, o conceito precisa ser pensamento.

Por fim é importante salientar que os sujeitos, de forma geral, apresentam-se em processo de desenvolvimento do pensamento conceitual, em concordância com as explicações da teoria Vygotskiana, no entanto, os conceitos mais evidentes e identificáveis limitavam-se aos cotidianos, fato que nos faz questionar a qualidade do processo educativo científico e cultural que se apresenta na escola e junto aos sujeitos da pesquisa.

Defendemos, portanto, que o movimento do pensamento humano apresenta-se evidente na escola e que os estudantes, ao dirigirem-se para essa instituição, precisam ter oportunidades de avançar ao pensamento cotidiano que aprenderam no seu dia-dia familiar e conquistar formas diferenciadas de pensamento, para que possam conquistar o tipo mais desenvolvido de pensamento humano, o conceitual, o qual possibilita uma visão abstrata, coerente e concreta da realidade, porque reconhecida nas suas múltiplas determinações, como apregoa a teoria histórico-cultural de desenvolvimento humano.

\section{REFERÊNCIAS}

ANJOS, R. E. O Desenvolvimento Psíquico na Idade de Transição e a Formação da Individualidade Para-Si: Aportes Teóricos Para a Educação Escolar de Adolescentes. 2013, 167 f. Dissertação (Mestrado em Educação Escolar) Faculdade de Ciências e Letras - UNESP/Araraquara.

LEONTIEV, A. N. O desenvolvimento do Psiquismo. 1 ed. Editora Moraes. São Paulo, 1978.

MARTINS, L. M. O Desenvolvimento do Psiquismo e a Educação Escolar: contribuições à luz da psicologia histórico cultural e da pedagogia histórico-crítica, 2011, 250 f. Tese de Livre-Docência, Departamento de Psicologia, Faculdade de Ciências - UNESP, Bauru-SP. 
MARTINS, L. M. Contribuições da psicologia histórico cultural para a pedagogia histórico-crítica. Exposição na Mesa Redonda "Marxismo e Educação: Fundamentos da Pedagogia Histórico-Crítica”. VII Colóquio Internacional Marx e Engels, IFCH-UNICAMP, 2012.

SAVIANI, D. Escola e democracia. 37ạ ed. Campinas: Autores Associados ,2005.

VIGOTSKI, L. S. A construção do pensamento e da linguagem. 2ạ Ed. WMF Martins Fontes, São Paulo, 2009.

VYGOTSKI, L. S. Obras Escogidas. Tomo II, Machado Grupo de Distribuición, S.L., Madrid, 2014.

VYGOTSKI, L. S. Obras Escogidas. Tomo IV, Machado Grupo de Distribuición, S.L., Madrid, 2012. 